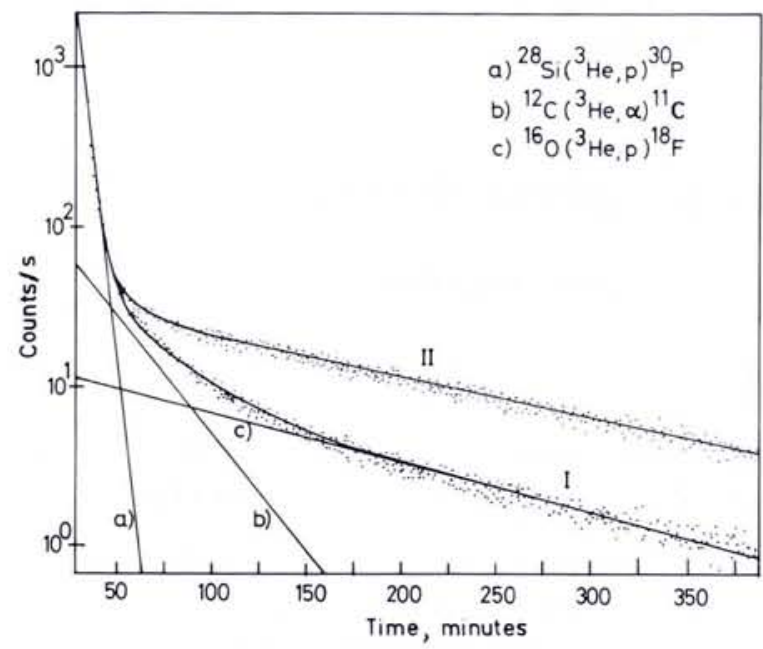

Fig. 5-Analysis of $C$ and $O$ in silicon by charged particle activation analysis.

gen in metals and semiconductors is essential for understanding the physical properties of these materials. The profiling of elements has already been mentioned, but it is worth considering the analysis method which yields results faster, even if only the integral number of impurity atoms is measured. All three elements mentioned above possess radioactive isotopes which decay by positron emission with reasonably short lifetimes, although long enough to guarantee statistically significant measurements. The reactions preferred are induced by ${ }^{3} \mathrm{He}$ particles as e.g. :

$$
\begin{array}{ll}
{ }^{12} \mathrm{C}\left({ }^{3} \mathrm{He}, \alpha\right)^{11} \mathrm{C} & \mathrm{t}_{1 / 2}=20.4 \mathrm{~min} \\
{ }^{14} \mathrm{~N}\left({ }^{3} \mathrm{He}, \alpha\right)^{13} \mathrm{~N} & \mathrm{t}_{1 / 2}=9.96 \mathrm{~min} \\
{ }^{16} \mathrm{O}\left({ }^{3} \mathrm{He}, \mathrm{p}\right)^{18} \mathrm{~F} & \mathrm{t}_{1 / 2}=109.7 \mathrm{~min}
\end{array}
$$

Activation times of the same order of magnitude as the decay lifetimes are required which means that this type of analysis is applicable to industrial conditions. Samples are activated by bombarding with ${ }^{3} \mathrm{He}$ particles of several $\mathrm{MeV}$ energy. Since the cross-section depends only slightly on energy in the range accessible to small accelerators, the bombarding energy is selected according to the depth from which information is wanted. In Fig. 5 the decay curves for two activated silicon samples are shown. I denotes a zone-refined silicon rod, whereas II denotes a Czochralskigrown silicon crystal. The decay curve a) indicates activation of the silicon matrix which decays with a half life of $2.5 \mathrm{~min}$. Curve b) gives the amount of carbon present in each sample, whereas c) allows the abundance of oxygen to be determined. The two samples produced by different processes contain oxygen concentrations which differ by an order of magnitude. As already mentioned, the time of analysis is reasonably short and the detection limits so far achieved are 8 $\mathrm{ppb}$ for carbon and $2 \mathrm{ppb}$ for oxygen in silicon. These values are far superior to those obtained with neutron activation.

\section{Final Remark}

The study of nuclear reactions over several decades has amassed a great deal of data about all existing isotopes. Many of them play an important role in materials science and in the solution of technical problems. Nuclear physics with its vast reservoir of information can contribute considerably to technical promark and companied the award read as follows: ballistic injection of electrons. gress, and the application of nuclear analysis methods is still growing. The improvement of detection limits is still an important task. Laboratories equipped with instrumentation for radiation detection and particle acceleration are well suited to carry out such investigations and many laboratories throughout the world are engaged in such work.

\section{REFERENCES}

1. Mayer J.W. and Rimini E., Ion Beam Handbook for Materials Anaysis, (Acad. Press, N.Y.) 1977.

2. Bethge K., Phys. BI. 40 (1984) 83.

3. Turkevich A.L., Franzgrote E.J. and Patterson J.H., Science 158 (1967) 636.

4. Proceedings of the Europhysics Conference on Nuclear Physics Methods in Materials Research, (Eds. K. Bethge, H. Baumann, H. Jex and F. Rauch) Darmstadt, Sept. 1980. 5. Chu W.K., Mayer J.W. and Nicolet M.A., Backscattering Spectrometry (Acad. Press. N.Y.) 1978.

6. Brauer E., Grüner R. and Rauch F., Ber. Bunsenges. Phys. Chem. 87 (1983) 341.

7. Weniger R., Dissertation Frankfurt (1984).

\title{
EPS 1985 Hewlett-Packard Europhysics Prize
}

As briefly announced in the January issue of Europhysics News the 1985 Hewlett-Packard Europhysics Prize has been awarded jointly to:

Dr. Jens Als-Nielsen of the Ris $\varnothing$ National Laboratory, Roskilde, Den-

Dr. Michael Pepper of the Cavendish Laboratory, Cambridge and the GEC's Hirst Research Centre, Wembley, UK.

The awards were presented on 20 March 1985 during the 5th EPS CMD General Conference held in Berlin (West). The official citation which ac-

"The importance of the dimensionality of physical systems has gained increased recognition in the last years both in condensed matter physics and material science, and in statistical physics. The work of the prize winners has in a significant way contributed to this. In particular they have shown that low-dimensional systems provide opportunities for ingenious experimentation to isolate and characterize physical features and new phenomena. The systems they have chosen for their studies have consisted of surfaces and suspended films of liquids, and of deposited layers and narrowly formed channels in metals and semiconductors. In studying these systems they have, often in a pioneering manner, applied refined techniques such as synchrotron $X$-ray diffraction and

From their research has come a wealth of information on novel types of collective states and quantum levels, such as the Peierls state and the quantized Hall effect. The results on the dependence of ordering and fluctuations on the dimensionality have in a gratifying manner verified recent developments in the theory of critical phenomena. The studies of electronic localization and transport in restricted or low-dimensional geometries have not only increased our understanding of these phenomena but may also lead to later technological applications.

The scientific achievements of Drs Als-Nielsen and Pepper within lowdimensional physics make them worthy recipients of the HewlettPackard Prize in condensed-matter physics for 1985."

Articles by the prize winners as well as a report on the CMD Conference will be carried in future issues of Europhysics News. 